\title{
The role of free radicals in liver damage
}

By M. U. Dianzani, Institute of General Pathology, University of Turin, Corso Raffaello 30, I0125 Turin, Italy

Increasing evidence has accumulated over the last few years on the involvement of free radical reactions in the genesis of the liver cell damage which characterizes several pathological conditions. Such conditions can be classified as (I) toxic liver damage, (2) iron overload, (3) dietary deficiencies or imbalances. In the first case the active free radicals are generated during the metabolic attack of the poison in the smooth endoplasmic reticulum (SER) of the liver cell, and are chemically related to the poison itself. Such types of radicals are able to covalently bind to cell structures, with their consequent functional modification. Free radicals, however, are also able to abstract hydrogen from suitable substances, so producing their oxidation. If the oxidized substance is a polyunsaturated fatty acid, $\mathrm{H}$ abstraction usually starts a chain reaction called 'lipid peroxidation'. This involves the production of lipid free radicals, as well as of other non-radical toxic products, especially carbonyls, that play an important role in cell damage. In the other two cases, i.e. Fe overload and dietary deficiencies or imbalances, oxygen free radicals may be involved, but lipid peroxidation is also important in the development of the damage.

In the present paper, a critical reconsideration of the relative importance of the different free radical mechanisms in the production of the cell damage is attempted. Most of the attention is focused on the toxic forms of liver damage, where existing knowledge allows more definite conclusions.

\section{Toxic liver damage}

Several forms of toxic liver damage have been claimed to involve free radical mechanisms, among which are those produced by haloalkanes, azodyes, alkylnitrosamines, adriamycin, paracetamol, paraquat and ethanol. In the present paper, only two forms of toxic injury, i.e. that produced by the haloalkane carbon tetrachloride and ethanol, will be discussed.

It is well known that $\mathrm{CCl}_{4}$-induced cell damage follows the electron transfer-dependent homolytic cleavage of the $\mathrm{C}-\mathrm{Cl}$ bond, occurring in the SER. As a consequence, a trichloromethyl free radical and a chlorine ion are formed (Slater, 1972):

$$
\mathrm{CCl}_{4} \stackrel{\mathrm{e}^{-}}{\longrightarrow} \mathrm{CCl}_{3}+\mathrm{Cl}^{-}
$$

According to Packer et al. ( 1978$), \mathrm{CCl}_{3}^{*}$ can easily react with $\mathrm{O}_{2}$ to give $\mathrm{CCl}_{3} \mathrm{O}_{2}^{*}$, the trichloromethylperoxy radical. A clear demonstration of the formation of $\mathrm{CCl}_{3}^{\circ}$ 
has been given not only in a cell-free system by pulse radiolysis (Packer et al. 1978), but also in biological systems, i.e. in the presence of isolated liver microsomes or hepatocytes in single-cell suspension by electron spin resonance (ESR) coupled to the spin trapping technique (Tomasi et al. 1980; Albano et al. I982). In the presence of $\mathrm{O}_{2}$, the ESR signal of $\mathrm{CCl}_{3}$ fades or disappears completely, due to the formation of $\mathrm{CCl}_{3} \mathrm{O}_{2}^{-}$, whose signal has not been positively detected as yet. Addition of promethazine (PMZ) has little effect on the formation of $\mathrm{CCl}_{3}$ but is able to block completely the formation of $\mathrm{CCl}_{3} \mathrm{O}_{2}^{*}$ from $\mathrm{CCl}_{3}$ and $\mathrm{O}_{2}$ (Packer et al. 1978, 1980). Thus PMZ has to be considered as a good scavenger of $\mathrm{CCl}_{3} \mathrm{O}_{2}^{-}$but not of $\mathrm{CCl}_{3}$. In vitro $\mathrm{CCl}_{3}^{*}$ reacts poorly with arachidonic acid or with other polyunsaturated fatty acids, while $\mathrm{CCl}_{3} \mathrm{O}_{2}^{*}$ reacts very quickly (Forni et al. 1983 ). The latter reaction is prevented by $\mathrm{PMZ}$ or by vitamin E. Very early after giving $\mathrm{CCl}_{4}$, the affected liver preparations display a great increase in lipid peroxidation. This was first demonstrated by the increase in the production of thiobarbituric acid (TBA)-reacting substances (mostly malonaldehyde) after treatment with $\mathrm{CCl}_{4}$ either in vivo or in vitro, and also by the rapid appearance of the diene conjugation band at $233 \mathrm{~nm}$.

As the onset of lipid peroxidation implies serious membrane damage, as well as the inhibition of several enzymes and cell functions, the problem to solve was whether the damage produced by $\mathrm{CCl}_{4}$ in liver cells was a consequence of covalent binding of $\mathrm{CCl}_{4}$ free radicals to suitable functional molecules (proteins, lipids, nucleotides, etc.), or whether it mainly depended on lipid peroxidation. Several authors essentially supported the first hypothesis (Castro et al. 1972; Gillette et al. 1974, I984; Reynolds \& Moslen, 1977); others were, however, in favour of lipid peroxidation as the major mechanism (Glende et al. 1976; Benedetti et al. 1977a). During the last few years, my group in Turin reached the conclusion that both mechanisms are involved in producing liver cell damage (Poli et al. 1981, 1983; Dianzani et al. 1984). Several criteria may be used to study the relative importance of haloalkylation and of lipid peroxidation in producing liver cell damage. The first criterion is that of the chronology of the lesions. Both $\mathrm{CCl}_{3}{ }_{3}$ and $\mathrm{CCl}_{3} \mathrm{O}_{2}$ are very short-lived, whereas lipid peroxidation is expected to produce damage more slowly with time, i.e. when the free radical chain reaction has succeeded in destroying a sufficient amount of membrane polyunsaturated fatty acids, what happens very shortly after giving the poison would be expected to depend mostly upon haloalkylation. With this point of view, one has also to consider that most free radical production must be confined to the very early period after poisoning, as free radicals rapidly destroy the enzymic system of the SER that is responsible for their production (Slater, I 972). In fact the chemical evidence of the presence of haloalkylation of lipids and proteins can be given within a few minutes after $\mathrm{CCl}_{4}$ treatment. However, the appearance of the diene conjugation band in microsomal phospholipids also occurs very early, but this only shows that the onset of the two events is practically simultaneous as expected from the knowledge that both participate in the reformation of covalent bonds: $\mathrm{H}$ is abstracted from lipids in the case of lipid peroxidation; carbon atoms are abstracted from proteins or lipids in 
the case of haloalkylation. The fact that $\mathrm{PMZ}$ is not very effective in preventing the formation of covalent binding, or the reactions of $\mathrm{CCl}_{3}$ in vitro (Packer et al. 1978), whereas it completely prevents the onset of lipid peroxidation, as well as the $\mathrm{CCl}_{3} \mathrm{O}_{2}^{-}$reactions in vitro, strongly favours the hypothesis of Slater ( 1972$)$ that $\mathrm{CCl}_{3}$ is mostly responsible for haloalkylation, whereas $\mathrm{CCl}_{3} \mathrm{O}_{2}^{*}$ is mostly responsible for the initiation of lipid peroxidation (see also Dianzani et al. 1984).

A second approach to the problem is the study of the intracellular topography of early damage. With this point of view, since free radicals are produced in the SER and they are short-lived, one would expect that haloalkylation may be considered when discussing the pathogenesis of the damage occurring in the SER or in its immediate surroundings but cannot be considered as responsible for the 'far' or 'remote' damage, i.e. damage occurring in cell sites far from the SER. Of course, this conclusion starts from the postulate that $\mathrm{CCl}_{4}$ is metabolized only in SER and that $\mathrm{CCl}_{4}$ free radicals are not only short-lived but are also the only free radicals produced. With regard to the first point, some criticism may come from the fact that it has been shown that $\mathrm{CCl}_{4}$ metabolites are also bound to the nuclear membranes, that actually derive from the SER, and possibly also to mitochondria (de Castro et al. 1984; Levy \& Brabec, 1984). A quite recent demonstration by Albano et al. (1985) that the strong antioxidant, vitamin $\mathrm{E}$, has no effect in preventing loss of calcium from mitochondria of isolated hepatocytes incubated in the presence of $\mathrm{CCl}_{4}$ seems to support this idea. With regard to the second point, Slater ( 1972 ) suggested that in the absence of $\mathrm{O}_{2}, \mathrm{CCl}_{3}$ might accumulate instead of $\mathrm{CCl}_{3} \mathrm{O}_{2}^{+}$, so favouring the expansion of the damage from SER to the surrounding structures. In addition, one has to consider the possibility of the interaction of $\mathrm{CCl}_{3}^{+}$with some $\mathrm{O}_{2}$-reactive species, for example $\mathrm{O}_{2}^{*-}$, that is produced to some extent during the oxidation of flavins. An interruption of the metabolizing chain at the level of cytochrome $P_{450}$ by $\mathrm{CCl}_{3}$ might increase the superoxide production at the level of the flavoprotein NADPH cytochrome $\boldsymbol{P}_{450}$ reductase $\left(E C\right.$ I.6.2.4). $\mathrm{O}_{2}$ may react with hydrogen, so forming hydrogen peroxide that generates the powerful $\mathrm{OH}^{*}$ free radical in the presence of $\mathrm{Fe}^{2+}$ :

$$
\mathrm{H}_{2} \mathrm{O}_{2}+\mathrm{Fe}^{2+} \longrightarrow \mathrm{OH}^{-}+\mathrm{OH}^{\cdot}+\mathrm{Fe}^{3+} \text { (Fenton reaction) }
$$

Moreover, $\mathrm{O}_{2}^{--}$can react with $\mathrm{H}_{2} \mathrm{O}_{2}$ in the presence of $\mathrm{Fe}^{3+}$ (Haber-Weiss reaction), forming oxygen, hydroxyl anion and hydroxyl free radical:

$$
\mathrm{O}_{2}^{--}+\mathrm{H}_{2} \mathrm{O}_{2} \stackrel{\mathrm{Fe}^{3+}}{\longrightarrow} \mathrm{OH}^{-}+\mathrm{OH}^{-}+\mathrm{O}_{2}
$$

We do not have any clear demonstration that this happens during $\mathrm{CCl}_{4}$-induced liver damage but we have no definite proof against it.

A third approach to the study of the relative importance of haloalkylation and of lipid peroxidation is the comparison of $\mathrm{CCl}_{4}$-poisoning with other pathological conditions characterized by high lipid peroxidation in the absence of haloalkylation. We did not include in this group ethanol or paracetamol, or 
bromobenzene poisonings, since their metabolic derivatives have been demonstrated to covalently bind to cell structures, a phenomenon identical to haloalkylation as regards the results. Cell damage following vitamin $\mathrm{E}$ deficiency, the in vitro ageing of homogenates or isolated cell particles, and Fe overload have been considered as prooxidant conditions without the occurrence of covalent binding. In the case of vitamin E deficiency, however, we cannot exclude side-effects since the damage develops slowly after deficiency. With $\mathrm{Fe}$, we are now aware that the kinetics of lipid peroxidation is different from that existing after $\mathrm{CCl}_{4}$ poisoning (Poli et al. $\mathrm{I}_{98}{ }_{5} \mathrm{c}$ ). The study of in vitro ageing has shown that the irreversible cell damage also seen in late stages of $\mathrm{CCl}_{4}$ poisoning is provoked by lipid peroxidation, while other changes present after $\mathrm{CCl}_{4}$ intoxication do not occur in this system. This latter finding gives indirect emphasis to haloalkylation as a mechanism of damage.

A fourth approach to the problem is finally the use of antioxidants or scavengers able to block lipid peroxidation without affecting haloalkylation. During the last few years, attention has been focused on two such substances, i.e. PMZ and vitamin $\mathrm{E}$. Both substances have been proved to be scarcely able to prevent haloalkylation after $\mathrm{CCl}_{4}$ poisoning, both in the whole animal and in hepatocyte models (G. Poli, E. Chiarpotto, F. Biasi, R. Carini, M. A. Pronzato, U. M. Marinari, M. Parola and M. U. Dianzani, unpublished results). On the other hand, both strongly inhibited the $\mathrm{CCl}_{4}$-induced formation of malonaldehyde, as well as of other aldehydes produced during lipid peroxidation. Table I summarizes the protective effects displayed by $\mathrm{PMZ}$ or vitamin $\mathrm{E}$ on different enzymic activities or cell functions. It has been shown that the deranging effect of $\mathrm{CCl}_{4}$ on several functions such as protein synthesis, activities of cytochrome $P_{450}$, aminopyrine demethylase and ornithine decarboxylase (EC 4.I.I.17), lipoprotein secretion, tubuline polymerization and cell $\mathrm{Ca}^{2+}$ homeostasis, is not protected by PMZ or vitamin $E$, whereas the inactivation of glucose-6-phosphatase $(E C$ 3.1.3.9) and of lactose synthase ( $E C$ 2.4.I.22), a marker of the Golgi vesicles, and the loss of plasma membrane integrity, monitored both by the dye exclusion test and by the lactate dehydrogenase release test, are prevented by these two substances (Dianzani \& Poli, 1984, 1985; Dianzani et al. 1984). On the basis of these findings we conclude that initial damage, at least in the early stages of $\mathrm{CCl}_{4}$ poisoning, is mostly caused by haloalkylation, whereas subsequent damage is attributable to lipid peroxidation. In fact, we have found that very early after giving ${ }^{14} \mathrm{CCl}_{4}$ both the protein and the lipid part of lipoproteins become labelled. The extent of labelling is practically identical in lipoprotein lipids inside the cell and in those found in the already 'secreted' micelles, whereas ${ }^{14} \mathrm{CCl}_{4}$ radioactivity bound to apolipoprotein is higher inside than outside the cell (Poli et al. 1983). This observation may allow the preliminary conclusion that the block of lipoprotein secretion is initially due to haloalkylation of apolipoprotein.

With regard to the mechanisms by which lipid peroxidation damages plasma membranes, we have not at the moment reached any definite conclusions. We have shown, however, that 4 -hydroxynonenal $(4-\mathrm{HNE})$, an aldehyde that is one of the 
Table I. The effects of promethazine or vitamin E† treatment on carbon tetrachloride poisoning of rat hepatocytes in single suspension

$\begin{array}{lcc}\text { Glucose-6-phosphatase }(E C \text { 3.1.3.9) activity } & \begin{array}{c}\mathrm{CCl}_{4} \text {-induced inhibition } \\ \text { or reduction (\%) }\end{array} & \begin{array}{c}\text { Protection exerted } \\ \text { by promethazine or } \\ \text { vitamin } \mathrm{E}\end{array} \\ \text { Cytochrome } P_{4 \text { sso }} \text { content } & 35-40 & \text { High or complete } \\ \text { Aminopyrine demethylase } & 30-35 & \text { Very low or absent } \\ \text { Protein synthesis } & 60-80 & \text { Very low or absent } \\ \text { Protein and lipoprotein secretion } & 40-50 & \text { Very low or absent } \\ \text { Plasma membrane integrity } & 60-80 & \text { Very low or absent } \\ \text { Galactosyl transferase activity } & \text { Time dependent } & \text { High or complete } \\ \text { High or complete }\end{array}$

-Cells were incubated at $37^{\circ}$ for 60 min with $129 \mu \mathrm{M}-\mathrm{CCl}_{4}$ in the presence or in the absence of 50-100 $\mu \mathrm{M}$-promethazine.

†Cells obtained from vitamin E-pretreated rats were incubated as for promethazine.

most toxic products of lipid peroxidation, can move from the production site (the SER) and reach remote parts of the cell, like the plasma membrane (Poli et al. I $985 c$ ). Moreover, we have shown that $4-\mathrm{HNE}$ is able to produce an early net increase in isolated plasma membrane activity of adenylate cyclase $(E C 4.6 .1 .1)$ at concentrations $\left(0.5 \times 10^{-7} \mathrm{M}\right)$ that can be found in $\mathrm{CCl}_{4}$-treated hepatocytes. Such a stimulatory effect is transient and it is followed by inhibition when the incubation time is prolonged or the final aldehyde concentration is increased. It is well known that adenylate cyclase is involved in the plasma membrane $\mathrm{Ca}^{2+}$ extrusion mechanism. Some authors (see Orrenius et al. 1984) consider the impairment of this pump as the main cause of cell death in several toxic conditions.

Lipid peroxidation produces cell damage by at least two mechanisms, i.e. by disruption of the anatomical integrity of membranes and by production of toxic compounds able to diffuse from the production site. The most important substances of this group are probably aldehydes that are produced in great amounts from peroxidizing lipids and are also 'secreted' from still viable hepatocytes after $\mathrm{CCl}_{4}$ stimulation (Poli et al. 1985 c).

A great number of enzymes and cell functions are impaired by aldehydes (see Dianzani, 1982) using intact cells or subcellular fractions as targets. In in vitro experiments the active concentrations of aldehydes are generally high (from $\mathrm{IO}^{-4}$ to $\left.\mathrm{IO}^{-5} \mathrm{M}\right)$. Such concentrations cannot be found within rat liver cells undergoing lipid peroxidation, so the importance of aldehyde production becomes questionable as far as it relates to aldehyde toxicity. In in vitro experiments, however, concentrations higher than those necessary for enzyme inhibition are needed, due to the presence in the preparations of large amounts of protective groups, mostly represented by substances containing amino and sulphydryl groups. In vivo, the situation may be different, as high concentrations of aldehydes may accumulate in defined cell areas in relation to the production site and the lipid solubility of the compounds. In principle, only one molecule of the aldehyde is requested to block an active $-\mathrm{SH}$ group in an enzyme molecule. There are, however, at least two 
effects of $4-\mathrm{HNE}$ that occur at concentrations which can be found in poisoned cells, and are therefore to be considered as toxic: (I) the already quoted stimulation, followed by inhibition of plasma membrane adenylate cyclase, occurring at HNE concentrations lower than $10^{-6} \mathrm{M}$ (Paradisi et al. 1985); (2) a chemotactic stimulation of polymorphonuclear leucocytes, occurring at $10^{-7} \mathrm{M}$ at its maximal rate, and being still measurable at concentrations of the order of $10^{-9}$ to $10^{-10} \mathrm{M}$ in the case of $4-\mathrm{HNE}$ and $10^{-12}$ to $10^{-13} \mathrm{M}$ in the case of 4-hydroxyoctenal (4-HOE) (Curzio et al. 1982).

The concentration of aldehydes within the cells does not depend only on the rate of their production but also on the rate of their removal by specific enzymes that may be involved in defined pathological situations. Aerobic removal of aldehydes is done by different types of aldehyde dehydrogenases. In anaerobic removal, other enzymes such as aldehyde reductase, alcohol dehydrogenase ( $E C$ I.I.I.I) and glutathione transferase ( $E C$ 2.5.1.1 8) play an important role. Moreover, aldehydes may be inactivated chemically by substances containing - SH groups. Among them the most important is certainly reduced glutathione (GSH). So, toxicity also depends on the initial concentration of GSH inside the cell, as well as on the rate of its regeneration through reduction of oxidized glutathione (GSSG) in the presence of NADH and by net synthesis.

\section{Ethanol poisoning}

Ethanol toxicity depends on ethanol metabolism mainly occurring in the cytosol through alcohol dehydrogenase action. The product of this dehydrogenation is acetaldehyde, which is thought to be responsible for several of the toxic effects of ethanol. It is now known, however, that this is not the only reason for its toxicity and free radical mechanisms have also been demonstrated. Free radicals formed during acute ethanol poisoning mainly belong to three types: (I) ethanol-derived free radicals; (2) oxygen free radical species formed during ethanol metabolism; (3) free radicals arising from lipid peroxidation.

Ethanol-derived free radicals have never actually been shown to be produced in vivo. Some authors, however, reported the recovery of free radical signals strictly related to the ethanol molecule (Cederbaum et al. 1979) by using different types of spin traps. Albano et al. (1985) recently succeeded to trap an ethyl-hydroxy-free radical $\left(\mathrm{CH}_{3}-\mathrm{C}^{\cdot} \mathrm{H}-\mathrm{OH}\right)$ by incubating liver microsomes with ethanol in the presence of the spin trap pyridine- $N$-oxide tert-butyl-phenyl-nitrone (POBN). The signal is intensified by animal pretreatment with phenobarbitol and decreased by addition of substances blocking the activity of the SER oxidative system. The signal, moreover, disappears when catalase (EC I.I1.r.6) is added to the system and intensified when catalase inhibitors such as $1 \mathrm{~mm}$-azide are present. $\mathrm{Fe}^{2+}$ strongly stimulates, whereas GSH decreases the formation of the signal. $\mathrm{OH}^{*}$ scavengers, such as mannitol or benzoate, reduce the signal (Albano et al. 1986). These results seem to favour the idea that, at least in this in vitro system, hydroxyethyl free radicals are not formed enzymically but are the consequence of the direct interaction of ethanol with $\mathrm{OH}^{\circ}$. During ethanol oxidation by the 
NADP-dependent microsomal system, $\mathrm{O}_{2}^{--}$and $\mathrm{H}_{2} \mathrm{O}_{2}$ are formed at the level of flavoprotein. In the presence of $\mathrm{Fe}^{2+}$ they may generate $\mathrm{OH}^{*}$ through a Fenton reaction. Of course, this event might also occur in vivo, especially when the concentration of $\mathrm{Fe}^{2+}$ within the cell is high and that of GSH is low. A possible reason for GSH decrease might be its interaction with acetaldehyde but this does not seem to be quantitatively very important. Another mechanism for GSH decline might also be its reaction with aldehydes derived from lipid peroxidation which is stimulated in the presence of ethanol both in vivo and in vitro. This second possibility for GSH decline is much more likely, and has been verified with both homogenates and microsomes in in vitro experiments (Dianzani, 1985).

The existence of high lipid peroxidation in ethanol poisoning has been debated over the past 20 years but it is now established that it does occur (for references see Dianzani, 1985). The reasons for ethanol-stimulation of lipid peroxidation are, however, still unclear and the study of the kinetics of aldehyde formation in this case is not yet complete. It has been shown, however, that relatively high amounts of 4 -HNE are produced. The most convincing hypothesis seems to be, in my opinion, that ethanol starts lipid peroxidation due to the intermediate production of $\mathrm{O}_{2}$ free radical species formed during its metabolism by the SER system. The free radical species involved might be $\mathrm{O}_{2}^{;-}$, formed at the level of flavoprotein, or $\mathrm{OH}^{*}$, formed from $\mathrm{H}_{2} \mathrm{O}_{2}$ due to a Fenton reaction. Ethylhydroxy free radicals might contribute to the initiation of lipid peroxidation, and one cannot exclude that other free radical species are also formed during acetaldehyde metabolism. Albano et al. (1985) detected the formation of free radicals with microsomes in the presence of acetaldehyde, but their nature remains uncertain. The addition of acetaldehyde to homogenates or microsomes, however, stimulates lipid peroxidation much more than ethanol does.

The most important feature of acute ethanol-induced liver damage is fat accumulation, necrosis being generally very low or absent. In chronic cases, however, necrosis becomes more relevant, increasing in direct relation to lipid peroxidation. It is noteworthy that the addition of either ethanol $(20 \mathrm{~mm})$ or acetaldehyde (100-200 $\mu \mathrm{M}$ ) to isolated hepatocytes, despite a strong increase of lipid peroxidation, is unable to block lipoprotein secretion. On the basis of these findings it is clear that the ethanol-induced increase of lipid peroxidation has no pathogenic relevance as far as it concerns fat accumulation. In chronic ethanol poisoning, however, the pathogenic role of lipid peroxidation certainly becomes more relevant. This might be due not only to the prolonged stimulation of lipid peroxidation with consequent decline in GSH levels (Comporti, 1978), but also to the fact that the relative choline deficiency occurring under such conditions may increase the susceptibility to peroxidation of arachidonic acid sited in SER membranes. Benedetti et al. $(1977 b)$ have demonstrated that, in the case of $\mathrm{CCl}_{4}$-poisoning, lipid peroxidation is initiated particularly at the level of the phosphatidylethanolamine constituents of SER membranes. It is also known that in choline deficiency, phosphatidylethanolamine substitutes for phosphatidylcholine in membranes. 


\section{Fe overload}

Fe overload produces liver cell damage, following the accumulation of this transition element in liver tissue (Bothwell et al. 1979). There are several forms of $\mathrm{Fe}$ overload, ranging from that seen in experimental animals given dietary $\mathrm{Fe}$ to the clinical syndromes, e.g. haemochromatosis and secondary haemosiderosis following repeated blood transfusions or hyperhaemolysis. The main features of liver cell damage in both experimental and clinical forms of $\mathrm{Fe}$ overload are segregation of Fe-containing material within lysosomes, lipofuscin accumulation and low-level necrosis. In chronic situations cirrhosis or cancer may develop.

In our laboratory, another model of $\mathrm{Fe}$ overload has been established: the incubation of isolated hepatocytes in the presence of externally added excess Fe. In these experimental conditions a strong ESR signal appears in the hepatocytes very early on and increases with time. This signal has been identified as due to a lipodienyl-type free radical, and therefore shows the onset and development of lipid peroxidation in the presence of $\mathrm{Fe}$. Great amounts of aldehydes are formed and accumulate both inside and outside the cells and most have been identified. We found that the stimulation of lipid peroxidation in terms of malonaldehyde production is much higher with $\mathrm{Fe}$ than with $\mathrm{CCl}_{4}$ and, therefore, that much higher amounts of the toxic aldehydes of the 4-hydroxy-2,3-trans-unsaturated series are also produced. The Fe-induced derangement of liver enzymes and functions are, however, much lower than those induced by $\mathrm{CCl}_{4}$ given at similar concentrations (Poli \& Gravela, 1982). This may be explained, at least in part, by the difference in lipid peroxidation kinetics which actually exists between the two conditions. Moreover, haloalkylation of unsaturated lipids after $\mathrm{CCl}_{4}$ poisoning, followed by their peroxidative disintegration, might produce more toxic aldehydes (for instance, haloalkylated aldehydes), as well as other types of toxic substances. Furthermore, a progressive leakage of cytosolic enzymes into the incubation medium takes place after $3^{-4} \mathrm{~h}$ incubation of liver cells also in the case of Fe-treated hepatocytes. This phenomenon appears to be gradual and probably related to the exhaustion of intracellular antioxidant systems. It is noteworthy that also in this case vitamin E pretreatment protected against lipid peroxidation, as well as against cell death (Poli et al. $1985 a, b$ ).

In relation to the intimate mechanism by which $\mathrm{Fe}$ stimulates lipid peroxidation, it seems clear that it must involve the intermediate formation of $\mathrm{O}_{2}$ free radical species, probably $\mathrm{OH}^{*}$. This might be produced either by the Fenton reaction (eqn (1)), or by the Haber-Weiss reaction (eqn (2)), or both.

\section{Other forms of dietary liver damage}

The involvement of free radical mechanisms has been proposed with regard to the pathogenesis of other dietary forms of liver damage. Among these particular examples are orotic acid-induced fatty liver and choline deficiency. In both cases high levels of lipid peroxidation have been reported (see Dianzani, 1978).

In orotic acid-induced fatty liver, increased lipid peroxidation has been related 
to the presence in liver cells of a redox system generating dihydro-orotic acid from orotic acid. Dihydro-orotic acid might be able to reduce $\mathrm{Fe}^{3+}$ to $\mathrm{Fe}^{2+}$, so stimulating lipid peroxidation. In any case, increased lipid peroxidation cannot explain the fat accumulation that seems to be related to the imbalance in protein synthesis induced by excess orotic acid.

Careful consideration must be given to choline deficiency. Several years ago, Ugazio et al. ( 1967 ) found increased amounts of lipofuscins in long-term choline deficiency but attributed it to an increase in the intrahepatic concentration of polyunsaturated fatty acids, that is to say of peroxidative substrates with consequent increased requirement of antioxidants. In the absence of increased intake of vitamin $\mathrm{E}$, a change in the peroxidative balance (Hartroft \& Porta, 1967) occurs and therefore lipid peroxidation levels rise. In this case, enhanced lipid peroxidation is the consequence, and not the cause, of fatty liver. More recently, Perera et al. ( 1985 ) used the short-term choline deficiency method and were able to detect very early increases in the diene conjugation band in microsomal phospholipids, as well as a stimulation in malonaldehyde production. The reason for the increase in lipid peroxidation in this situation remains unclear. Tentatively, attention can be drawn to the fact that in choline-deficiency, phosphatidylethanolamine, a preferential structure for lipid peroxidation, replaces phosphatidylcholine. Increased susceptibility of the substrate, however, cannot explain the onset of lipid peroxidation but only part of the propagation reactions. Some other metabolic derangements probably related to the high dietary intake of fatty acids necessary to obtain this experimental toxic condition seem to be involved.

\section{REFERENCES}

Albano, E., Bellomo, G., Carini, R., Biasi, F., Poli, G. \& Dianzani, M. U. (1985). FEBS Letters $192,184-188$.

Albano, E., Lott, K. A. K., Slater, T. F., Stier, A., Symons, M. C. R. \& Tomasi, A. (Ig82). Biochemical fournal 204,593-603.

Albano, E., Tomasi, A., Goria Gatti, L., Carini, R., Vanini, V. \& Dianzani, M. U. (1986). In Free Radical Cell Damage and Disease [C. Rice Evans, editor]. London: Richelieu.

Benedetti, A., Casini, A. F., Ferrali, M. \& Comporti, M. (1977a). Experimental Molecular Puthology 27, 309-323.

Benedetti, A., Casini, A. F., Ferrali, M. \& Comporti, M. (1977b). Chemical and Biological Interactions $17,167-183$.

Bothwell, T. H., Charlton, R. W., Cook, J. D. \& Finch, C. A. (1979). Iron Metabolism in Man, pp. 105-1 20. Oxford: Blackwell.

Castro, J. A., Diaz Gomez, M. I., de Ferreira, E. C., de Castro, C. R., D'Acosta, N. \& Fenos, O.M. (1972). Biochemical and Biophysical Research Communications 47, 314-321.

Cederbaum, A. I., Miwa, G., Cohen, G. \& Lin A. Y. H. (1979). Biochemical and Biophysical Research Communications $91,747-754$.

Comporti, M. (1978). In Biochemical Mechanisms of Liver Injury, pp. 449-516 [T. F. Slater, editor]. New York: Academic Press.

Curzio, M., Torrielli, M. V., Giroud, J. P., Esterbauer, H. \& Dianzani, M. U. (1982). Research Communications in Chemical Pathology and Pharmacology 36, 463-476.

de Castro, C. R., Bernacchi, A. S., Villaruel, M. C., Fernadez, G. \& Castro, J. A. (1984). Agents and Actions $15,664-667$.

Dianzani, M. U. (1978). In Biochemical Mechanisms of Liver Injury, pp. 45-95 [T. F. Slater, editor]. New York: Academic Press. 
Dianzani, M. U. (1982). In Free Radicals, Lipid Peroxidation and Cancer, pp. 129-158 [D. C. H. McBrien and T. F. Slater, editors]. London: Academic Press.

Dianzani, M. U. (1985). Alcohol and Alcoholism 20, 161-1 73 .

Dianzani, M. U., Marinari, U. M. \& Poli, G. (1984). Proceedings of IUPHAR gth International Congress of Pharmacology, pp. 259-264 [W. Paton, J. Mitchell and P. Turner, editors]. London: Macmillan Press Ltd.

Dianzani, M. U. \& Poli, G. (1984). In Frontiers of Gastrointestinal Research, vol. 8. pp. I-13 [P. Gentilini and M. U. Dianzani, editors]. Basel: Karger.

Dianzani, M. U. \& Poli, G. (1985). In Free Radicals in Liver Injury, pp. 149-158 [M. U. Dianzani, G. Poli, T. F. Slater and K. H. Cheeseman, editors]. Oxford: IRL Press Ltd.

Forni, L. G., Packer, J. E., Slater, T. F. \& Willson, R. L. (1983). Chemical and Biological Interactions 45, I 7 I-I 77 .

Gillette, J. R., Laus, S., Monks, T. J. \& Phol, L. R. (1984). Proceedings of IUPHAR gth International Congress of Pharmacology, pp. $25^{\mathrm{I}-257}$ [W. Paton, J. Mitchell and P. Turner, editors]. London: Macmillan Press Ltd.

Gillette, J. R., Mitchell, J. R. \& Brodie, B. B. (1974). Annual Review of Pharmacology 14, $271-288$.

Glende, E. A., Hruszkewycz, A. M. \& Recknagel, R. O. (1976). Biochemistry and Pharmacology $25,2163-2170$.

Hartroft, W. S. \& Porta, E. A. (1967). In Present Knowledge in Nutrition, 3rd ed., pp. 28-31 [The Nutrition Foundation, editor]. New York: The Nutrition Foundation Inc.

Levy, G. N. \& Brabec, M. J. (1984). Toxicology Letters 22, 229-234.

Orrenius, S., Thor, H., Bellomo, G. \& Moldeus, P. (1984). Proceedings of IUPHAR gth International Congress of Pharmacology, pp. 57-72 [W. Paton, J. Mitchell and P. Turner. editors]. London: Macmillan Press Ltd.

Packer, J. E., Slater, T. F. \& Willson, R. L. (I978). Life Sciences 23, 2617-2620.

Packer, J. E., Willson, R. L., Bahnemann, D. \& Asmus, K.-D. (1980). Fournal of the Chemical Society, Perkin Transactions 2, 296-299.

Paradisi, L., Panagini, C., Parola, M., Barrera, G. \& Dianzani, M. U. (1985). Chemical and Biological Interactions 53, 209-217.

Perera, M. I. R., Demetris, J., Katyal, S. L. \& Shinozouka, H. (1985). Cancer Research 45, $2533^{-2538 .}$

Poli, G., Albano, E., Biasi, F., Carini, R., Cecchini, G., Bellomo, G. \& Dianzani, M. U. (1985a). In Free Radicals in Liver Injury, pp. 207-21 5 [M. U. Dianzani, G. Poli, T. F. Slater and K. H. Cheeseman, editors]. Oxford: IRL Press Ltd.

Poli, G., Cheeseman, K. H., Slater, T. F. \& Dianzani, M. U. (1981). Chemical and Biological Interactions 37, $13-24$.

Poli, G., Chiarpotto, E., Albano, E., Biasi, F., Cecchini, C. \& Dianzani, M. U. (1985b). In Chronic Liver Disease, pp. 35-50 [M. U. Dianzani and P. Gentilini, editors]. Basel: Karger.

Poli, G., Chiarpotto, E., Albano, E., Biasi, F., Cecchini, G. \& Gravela, E. (1983). Chemical and Biological Interactions 43, 253-261.

Poli, G., Dianzani, M. U., Cheeseman, K. H., Slater, T. F., Lang. J. \& Esterbauer, H. (1985c). Biochemical fournal $227,629-638$.

Poli, G. \& Gravela, E. (1982). In Free Radicals, Lipid Peroxidation and Cancer, pp. 21 5-242 [D. H. C. McBrien and T. F. Slater, editors]. London: Academic Press.

Reynolds, E. S. \& Moslen, M. T. (1977). Biochemical and Biophysical Research Communications $57,747-760$.

Slater, T. F. (1972). Free Radical Mechanisms in Tissue Injury. London: Pion Ltd.

Tomasi, A., Albano, E., Lott, K. A. K. \& Slater, T. F. (1980). FEBS Letters 122, 303-306.

Ugazio, G., Gabriel, L. \& Burdino, E. (1967). Lo Sperimentale 11 7, 1-1 7 . 